\title{
The role of the clinical cardiologist in a cardiovascular prevention program
}

\section{El papel del cardiólogo clínico en un programa de prevención cardiovascular}

\author{
Nicolás Jaramillo Gómez ${ }^{\mathrm{a}, \mathrm{b}, \mathrm{c}}$ \\ a Hemodynamics Laboratory, Clínica Las Américas, Medellín, Colombia \\ b Cardiometabolic Diseases CEMDE - CES, Medellín, Colombia \\ c Universidad CES, Medellín, Colombia
}

Received 29 August 2016; accepted 1 September 2016

Available online 17 November 2016

To begin such an engrossing editorial subject, an accurate and conceptually universal definition of the prevention of cardiovascular disease (cardiovascular disease) will be considered. Accordingly, the definition adopted by the 6th Joint Task Force of the European Society of Cardiology ${ }^{1}$ will be assumed. This body defines it as a set of coordinated actions aimed at a population or an individual, with the purpose of eliminating or minimizing its impact and the disabilities associated with it. ${ }^{2}$

When this definition is contextualized, it is clear that in light of a disease that is still today the world leader in morbidity and mortality, prevention becomes a priority, especially when tendencies towards a decline in coronary disease have been observed since the $80 \mathrm{~s}$ in nations and regions with a high-income population. ${ }^{3}$ This guideline is directly related to the preventive measures which were successfully put into effect, including the enacting, in many countries, of anti-tobacco laws, but is not seen in nations such as ours, where we continue to see a progressive and concerning escalation in the incidence of obesity, sedentarism, and diabetes mellitus, in terms of modifiable cardiovascular risk factors. No less alarming is the scant effectiveness in achieving goals in the treatment of high

DOI of original article:

http://dx.doi.org/10.1016/j.rccar.2016.09.008

E-mail address: nicojaramillo27@gmail.com frequency pathologies in our context, such as arterial hypertension, hypercholesterolemia and diabetes itself, due to a lack of compliance for multiple reasons.

An evaluation of the direct causes of these tendencies shows that the first circumstance causing the ongoing rise in chronic noncommunicable diseases is modern life styles, which, beginning with the process of industrialization, changed the course of the world, and which, while providing a different quality of life, are also taking their toll.

The advent of automation, assisted mobility, and the internet created a completely sedentary environment leading to an excessive caloric intake which is difficult to control, resulting in increased obesity as a prevalent disease worldwide, and bringing with it all its adversities. ${ }^{4}$ Within these tendencies, it is even more concerning to see how obesity has been concentrated in the very young.

Joined with these changes is the ever greater capacity of having health care treatment facilities in our communities, and great technological advances which, applied to medicine, have resulted in an increased life expectancy and ultimately a very significant one in those over 65 years of age, which leads to having people with greater morbidities and noncommunicable chronic diseases with a high economic impact on the health system of any country. ${ }^{5}$

In this scenario, it is pertinent to come back to the article: "ever too soon, never too late for prevention", published in 2014 in the Revista Española de Cardiología, 
which gives an overview of primordial and primary prevention across an individual's life span. The authors describe novel strategies for achieving healthy life habits which will prevent the adoption of cardiovascular risk factors; in other words, practicing primordial prevention and creating interventions designed to modify cardiovascular risk factors in order to avoid the initial cardiovascular event. ${ }^{6}$

In the local context, we cardiologists are faced with a scenario that could well be summarized as follows:

1. Life habits which make our populations susceptible to noncommunicable chronic diseases: high calorie intake leading to obesity, internet penetration and facilitated mobility resulting in sedentarism, and the use of cigarettes and highly addictive substances.

2. An increase in type 2 diabetes, secondary to these life habits.

3. A change in demographic tendencies, with a significant increase in the population over the age of 65.

4. Lack of adherence to pharmacological treatments and to heart healthy life habits.

Based on the previous scenario, Colombia's health system has been developing and has begun to implement a more comprehensive and possibly more effective vision of noncommunicable chronic disease management, including cardiovascular disease and diabetes, with a plan for how to maintain compliance with the program, creating a sense of belonging, and providing the patient with more knowledge of his/her own disease and what self-care implies.

\section{Current role of the cardiologist in the challenge taken on by our health care system}

The work group is generally made up of a medical specialist accompanied by an expert primary care physician, a nurse, psychologist, pharmacist, nutritionist and a cardiac rehabilitation program. This work team recognizes the need to work with the knowledge provided by the cardiologist and his/her expert primary physician, together with a positive environment generated by the vision of positive cardiovascular health which arises from the integration of positive psychology and preventive cardiology. ${ }^{7}$

With regard to the compliance strategy, which is a fundamental point in secondary prevention, (as shown by Freeman et al. in their article, where it had an impact on $80 \%$ of the final outcomes in post-myocardial infarction patients), a minimum of $40 \%$ of compliance should be maintained in order to retain the impact, ${ }^{8}$ a situation which is reinforced by the group nurse and pharmacist.

Likewise, the nutritional aspect, according to the National Institute for Health and Care Excellence, "NICE"), speaks of how mortality can be impacted. Coronary disease could be cut in half with just modest reductions in cardiovascular risk factors, since it suggests that by establishing eight dietary priorities, deaths due to cardiovascular disease could also be lowered by half, ${ }^{9}$ thus becoming another fundamental element in the comprehensive management of the cardiovascular patient.

Likewise, rehabilitation and exercise medicine enter the picture, under the supervision of sports medicine physicians, physiatrists, and exercise specialists who propose, (based on the work of Professor Antikainen recently revealed at the European Congress on cardiology in Rome: Leisure time physical activity reduces the risk of cardiovascular death and an acute CVD event also among older adults), that moderate physical activity reduces the risk of a cardiovascular event by more than $30 \%$ and that high levels of exercise may achieve greater risk reductions. ${ }^{10}$ In this way, an exceptional work group is formed which manages to have an impact on disease through the use of simple and cost-efficient resources.

As leader, the cardiologist should be part of the whole process, administer the resources and direct each line of care. In order to carry out these activities he/she should be familiar with, and make a greater commitment to, the comprehensive models, giving positive feedback and directing them on behalf of health care institutions, health care administration institutions, the health group and the patient.

It is a commitment, and practically an obligation, to the patient for the cardiologist to facilitate and implement this system, in order to impart a true concept of health with which disease may be controlled by providing basic and specialized health care. This health care includes a degree of education which is considered secondary prevention, where the primary objective is to seek drug compliance and a preservation of healthy life habits through providing support in supervised exercise, as well as motivation to acquire the habit of frequent attendance at the established program. Family or primary caregiver support of the patient is not left out, as they also receive education, in this way closing the complete cycle with a little prevention.

All these actions are measured according to their immense impact on morbidity and mortality in patients with cardiovascular disease.

In summary, the clinical cardiologist is called to action as leader and possessor of knowledge, and to create an appropriate work team which shares those same interests.

\section{References}

1. Piepoli MF, Hoes AW, Agewall S, Albus C, Brotons C, Catapano AL, et al. 2016 European Guidelines on cardiovascular disease prevention in clinical practice: The Sixth Joint Task Force of the European Society of Cardiology and Other Societies on Cardiovascular Disease Prevention in Clinical Practice (constituted by representatives of 10 societies and by invited experts). Developed with the special contribution of the European Association for Cardiovascular Prevention \&amp; Rehabilitation (EACPR). Eur Heart J. 2016;37:2315-81.

2. Porta MS. International Epidemiological Association, editors. A dictionary of epidemiology. $5^{\text {th }}$. ed. Oxford; New York: Oxford University Press; 2008.

3. Moran AE, Forouzanfar MH, Roth GA, Mensah GA, Ezzati M, Murray CJ, et al. Temporal trends in ischemic heart disease mortality in 21 world regions, 1980 to 2010: the Global Burden of Disease 2010 study. Circulation. 2014;129:1483-92.

4. Finucane MM, Stevens GA, Cowan MJ, Danaei G, Lin JK, Paciorek $\mathrm{CJ}$, et al. National, regional, and global trends in body-mass index since 1980: systematic analysis of health examination surveys and epidemiological studies with 960 country-years and 9.1 million participants. Lancet. 2011;377:557-67. 
5. Pemberthy C, Jaramillo-Gómez N, Velásquez Mejía CA, CardonaVélez J, Contreras-Martínez H, Jaramillo-Restrepo V. Conceptos actuales sobre el envejecimiento y la enfermedad cardiovascular. Rev Colomb Cardiol. 2016;23:210-7.

6. Castellano JM, Penalvo JL, Bansilal S, Fuster V. Promoción de la salud cardiovascular en tres etapas de la vida: Nunca es demasiado pronto, nunca demasiado tarde. Rev Esp Cardiol. 2014;67:731-7.

7. Labarthe DR, Kubzansky LD, Boehm JK, Lloyd-Jones DM, Berry JD, Seligman MEP. Positive Cardiovascular Health. J Am Coll Cardiol. 2016;68:860-7.

8. Bansilal S, Castellano JM, Garrido E, Wei HG, Freeman A, Spettell $C$, et al. Assessing the Impact of Medication Adherence on Long-Term Cardiovascular Outcomes. J Am Coll Cardiol. 2016;68:789-801.

9. Collins M, Mason H, O’Flaherty M, Guzman-Castillo M, Critchley $\mathrm{J}$, Capewell S. An economic evaluation of salt reduction policies to reduce coronary heart disease in England: a policy modeling study. Value Health. 2014;17:517-24.

10. Barengo NC, Antikainen RL, Borodulin K, et al. Leisure time physical activity reduces the risk of cardiovascular death and an acute CVD event also among older adults. In: European Society of Cardiology 2016 Congress. 2016. 